\title{
Determination of the absolute bioavailability of oral imatinib using a stable isotopically labeled intravenous imatinib-d8 microdose
}

\author{
Jeroen Roosendaal ${ }^{1}$ (D) Stefanie L. Groenland ${ }^{2} \cdot$ Hilde Rosing $^{1} \cdot$ Luc Lucas $^{1} \cdot$ Nikkie Venekamp ${ }^{1} \cdot$ Bastiaan Nuijen ${ }^{1}$. \\ Alwin D. R. Huitema ${ }^{1,3}$ • Jos H. Beijnen ${ }^{1,4} \cdot$ Neeltje Steeghs ${ }^{2}$
}

Received: 5 January 2020 / Accepted: 30 April 2020 / Published online: 19 May 2020

(C) The Author(s) 2020

\begin{abstract}
Purpose The aim of this study was to ascertain whether the absolute bioavailability of oral imatinib (Glivec®) during steady state plasma pharmacokinetics in cancer patients could be determined through a concomitant intravenous administration of a single $100 \mu \mathrm{g}$ microdose of deuterium labeled imatinib (imatinib-d8). Secondly, the usefulness of liquid chromatography-tandem mass spectrometry (LC-MS/MS) was investigated for simultaneous analysis of orally and intravenously administered imatinib.

Methods Included patients were on a stable daily dose of $400 \mathrm{mg}$ oral imatinib prior to study participation. On day 1, patients received a $100 \mu \mathrm{g}$ intravenous imatinib-d8 microdose $2.5 \mathrm{~h}$ after intake of the oral dose. Plasma samples were collected for $48 \mathrm{~h}$. Imatinib and imatinib-d8 concentrations were simultaneously quantified using a validated LC-MS/MS assay. The absolute bioavailability was calculated by comparing the dose-normalized exposure with unlabeled and stable isotopically labeled imatinib in plasma.

Results A total of six patients were enrolled. All patients had a history of gastrointestinal stromal tumors (GIST). The median absolute bioavailability of oral imatinib at steady state was 76\% (range 44-106\%). Imatinib and imatinib-d8 plasma concentrations were quantified in all collected plasma samples, with no samples below the limit of quantification for imatinib-d8.

Conclusion The absolute bioavailability of imatinib was successfully estimated at steady state plasma pharmacokinetics using the stable isotopically labeled microdose trial design. This study exhibits the use of a stable isotopically labeled intravenous microdose to determine the absolute bioavailability of an oral anticancer agent in patients with LC-MS/MS as the analytical tool.
\end{abstract}

Keywords Imatinib $\cdot$ Microdosing $\cdot$ Absolute bioavailability $\cdot$ Stable isotope labeled $\cdot$ Steady state

Electronic supplementary material The online version of this article (https://doi.org/10.1007/s00228-020-02888-y) contains supplementary material, which is available to authorized users.

Jeroen Roosendaal

j.roosendaal@nki.nl

1 Department of Pharmacy \& Pharmacology, Netherlands Cancer Institute - Antoni van Leeuwenhoek, Plesmanlaan 121, 1066 CX Amsterdam, The Netherlands

2 Department of Medical Oncology and Clinical Pharmacology, The Netherlands Cancer Institute - Antoni van Leeuwenhoek, Amsterdam, The Netherlands

3 Department of Clinical Pharmacy, University Medical Center, Utrecht University, Utrecht, The Netherlands

4 Division of Pharmacoepidemiology and Clinical Pharmacology, Faculty of Science, Utrecht Institute for Pharmaceutical Sciences, Utrecht University, Utrecht, The Netherlands

\section{Introduction}

The last decade has shown an increasing number of anticancer drugs that are administered orally. [1-3] This so-called "intravenous to oral switch" in oncology has resulted in an increased attention on the investigation of the absolute bioavailability during clinical drug development. Determining the absolute oral bioavailability of a new drug candidate facilitates the identification of potential developmental challenges such as absorption and first pass metabolism during the clinical development of a drug. Hence, the assessment of the absolute bioavailability is also crucial for the development of optimized oral formulations. As a result, data on the absolute bioavailability of novel oral drugs is now increasingly requested by the FDA and EMA $[4,5]$.

The conventional way to assess the absolute oral bioavailability is by using a two-period crossover study design, where an intravenous dose and an oral dose are administered to a 
study subject with a washout period in between. The absolute bioavailability is then calculated by dividing the plasma exposure after oral administration by the plasma exposure after intravenous administration. A limitation of this design is that for drugs that are poorly soluble in aqueous media, it might be impossible to develop an intravenous formulation at therapeutic strength. In addition, it assumes linear pharmacokinetics and constant clearance between the oral and intravenous dose event, which might not always be the case for drugs demonstrating a high intra-patient variability. This may result in a systemic error in the determination of the absolute bioavailability. [6]

A study design of co-administering an intravenous isotopically labeled microdose $(\leq 100 \mu \mathrm{g}$, less than $1 / 100$ th of the therapeutic dose) with a therapeutic oral dose provides a solution to these problems. Because only a small amount of drug needs to be dissolved in an intravenous formulation, drug solubility issues can be circumvented. In addition, according to the current regulatory guidelines, clinical intravenous microdose studies could be carried out without additional toxicity investigations, saving costs, and time associated with intravenous drug development. [7] Furthermore, because the intravenous microdose is administered during the same dose event as the oral therapeutic dose, the study duration is shortened and intra-occasion variability is not an issue, resulting in a more accurate determination of the absolute bioavailability and increased patients convenience.

Absolute bioavailability microdose trials can be performed using either radiolabeled or stable isotopically labeled drug processed into an intravenous formulation. In recent years, accelerator mass spectrometry (AMS) to measure a radiolabeled microdose has been utilized to support several clinical absolute bioavailability studies. [8] A drawback of AMS is that sample analysis is labor and time intensive, expensive, and that AMS is only available in a limited number of places dedicated to biomedical research worldwide. [9] An alternative analytical approach for conducting microdose studies is using liquid chromatography coupled to tandem mass spectrometry (LC-MS/ MS) to quantitate both the intravenous and the oral drug. Because both labeled and unlabeled drug can be measured simultaneously with LC-MS/MS, it is an elegant and cost-effective alternative to AMS. [9, 10]

For the group of tyrosine kinase inhibitors, an important class of novel oral anticancer agents, it has been demonstrated that for many drugs registered in the past years, the absolute bioavailability has not been assessed at the time of drug licensing. [3] One reason for this might be that poor drug solubility hampers the development of an aqueous intravenous dose at therapeutic strength, making it almost impossible to use the conventional crossover trial design. In this trial, we used imatinib, a tyrosine kinase inhibitor used for the treatment of chronic myeloid leukemia (CML) and gastrointestinal stromal tumors (GIST), to demonstrate the potential of using a stable isotopically labeled $100 \mu \mathrm{g}$ microdose in combination with LC-MS/MS to assess the absolute bioavailability.

The objective of this study was to ascertain whether the absolute bioavailability of oral imatinib (Glivec $($ ) during steady state plasma pharmacokinetics in cancer patients could be determined through a concomitant intravenous administration of a single $100 \mu \mathrm{g}$ microdose of deuterium labeled imatinib (imatinib-d8). Secondly, the usefulness of liquid chromatography-tandem mass spectrometry (LC-MS/MS) is investigated for simultaneous analysis of orally and intravenously administered imatinib.

\section{Materials and methods}

\section{Study design and sample collection}

This was a single center, open-label study in which the absolute bioavailability of imatinib (Figure 1a) was determined at steady state by concomitant administration of an intravenous microdose of stable isotopically labeled imatinib-d8 (Figure 1b). Figure 2 provides a schematic overview of the study design. On day 1 , patients received a single intravenous microdose of imatinib-d8, next to the standard treatment of imatinib $400 \mathrm{mg}$ once daily (Glivec $($ ). After intake of imatinib at approximately 08:30 a.m., a $100 \mu \mathrm{g}$ imatinib-d8 microdose was administered intravenously as a bolus injection at the estimated maximum plasma concentration $\left(t_{\max }\right)$ of oral imatinib $(2.5 \mathrm{~h}$ post oral dose). Oral imatinib intake was not interrupted for the duration of the study. The study (Netherlands Trial Register, NTR7642, www.nederlandstrialregister.nl) was approved by both the Medical Ethics Committee of The Netherlands Cancer Institute, Amsterdam, The Netherlands, as well as the competent authority (Centrale Commissie Mensgebonden Onderzoek, CCMO). The study was conducted in accordance with the Declaration of Helsinki. All participants provided written informed consent prior to study assessments.

\section{Patients}

Patients $\geq 18$ years of age, treated with imatinib $400 \mathrm{mg}$ once daily in the morning for at least 7 days (steady state plasma concentrations), were included. Subjects needed to have acceptable organ function, as evidenced by laboratory data: aspartate aminotransferase (ASAT) and alanine aminotransferase $($ ALAT) $<5 \times$ the upper limit of normal (ULN), total serum bilirubin $\leq 2 \times$ ULN, and renal function as defined by glomerular filtration rate (GFR MDRD) $>40 \mathrm{~mL} / \mathrm{min} / 1.73 \mathrm{~m}^{2}$. Subjects who received treatment with inhibitors or inducers of CYP3A4 were excluded. 
Fig. 1 Molecular structures. a Imatinib. b Imatinib-d8 a<smiles>Cc1ccc(NC(=O)c2ccc(CN3CCN(C)CC3)cc2)cc1Nc1nccc(-c2cccnc2)n1</smiles>

b<smiles>[2H]C1([2H])N(C)C([2H])([2H])C([2H])([2H])N(Cc2ccc(C(=O)Nc3ccc(C)c(Nc4nccc(-c5cccnc5)n4)c3)cc2)C1([2H])[2H]</smiles>

\section{Treatment}

Patients received $400 \mathrm{mg}$ imatinib (Glivec $($ ) tablets once daily in the morning as part of routine clinical care. According to the drug label, imatinib was ingested concomitant with a meal. [11] Meals were not standardized. The reference drug imatinib-d8 (Toronto Research Chemicals, ON, Canada) was formulated in the hospital pharmacy of The Netherlands Cancer Institute and was supplied as a $0.1 \mathrm{mg} / \mathrm{mL}$ in $\mathrm{NaCl}$ $0.9 \%$ solution for intravenous injection.

\section{Sample collection, processing, and analysis}

From day 1 to day 3, pharmacokinetic sampling was performed. Blood samples were collected at predose, 0.5, 1, 1.5, 2, 2.5 (pre intravenous microdose), 3, 3.5, 4, 4.5, 5, 6, $8,12,24$ (pre day 2 oral dose), and $48 \mathrm{~h}$ (pre day 3 oral dose), after oral imatinib intake.

Peripheral blood for quantification of imatinib and imatinib$\mathrm{d} 8$ was drawn in 4-mL $\mathrm{K}_{2}$ EDTA tubes and centrifuged directly after collection $\left(1500 \mathrm{~g}, 10 \mathrm{~min}, 4^{\circ} \mathrm{C}\right)$. Plasma was stored at $80^{\circ} \mathrm{C}$ until analysis. A validated LC-MS/MS assay was used for the simultaneous quantification of imatinib and imatinib- $\mathrm{d} 8$. [12] Routine sample analysis acceptance criteria for bioanalytical data according to FDA and EMA guidelines $[13,14]$ were applied and results were reported using the Analyst 1.6.2. software (Sciex, Framingham, MA, USA).

\section{Pharmacokinetic analysis and absolute bioavailability calculation}

Imatinib and imatinib-d8 plasma concentrations were used to determine the maximum observed plasma concentration $\left(C_{\max }\right)$, time to reach maximum plasma concentration $\left(T_{\max }\right)$, area under the plasma concentration-time curve from time zero to $24 \mathrm{~h}\left(\mathrm{AUC}_{0-24 \mathrm{~h}}\right)$ for imatinib, and from time zero to infinity $\left(\mathrm{AUC}_{0 \text {-inf }}\right)$ for imatinib-d8, the terminal phase half-life $\left(t^{1} / 2\right)$ and the elimination rate constant from the central compartment $\left(k_{\mathrm{e}}\right)$, the volume of distribution $\left(V_{\mathrm{d}}\right)$, and total plasma clearance (CL). Parameters were calculated using plasma concentration-time curves obtained from 0 to $24 \mathrm{~h}$ for imatin$\mathrm{ib}$, and from 0 to $48 \mathrm{~h}$ for imatinib-d8. Non-compartmental analysis was performed using $\mathrm{R}$ version 3.0.1. [15]

As the exposure at steady state plasma pharmacokinetics during the dose interval is equivalent to the exposure from zero to infinity following a single administration [16], the $\mathrm{AUC}_{0-24 \mathrm{~h}}$ for imatinib and the $\mathrm{AUC}_{0 \text {-inf }}$ for imatinib-d8 could be used to calculate the absolute bioavailability without dose interruptions for the patients.

The absolute bioavailability $(F)$ of oral imatinib was calculated as the ratio of dose-normalized exposures of the oral (po) imatinib and intravenous (iv) imatinib-d8 gift expressed as a percentage using the following formula:

$F(\%)=\frac{\left[\mathrm{AUC}_{0-24}\right]_{\mathrm{po}} / \text { Dose }_{\mathrm{po}}}{\left[\mathrm{AUC}_{0-\mathrm{inf}}\right]_{\mathrm{iv}} / \text { Dose }_{\mathrm{iv}}} \times 100$

\section{Results}

A total of six patients have been included, with a median age of 65 years (range 52-72). Of these patients, 50\% received adjuvant imatinib treatment for GIST and $50 \%$ were treated in the metastatic setting. An overview of patient baseline characteristics can be found in Table 1 .

All included patients were evaluable for pharmacokinetic analysis. Mean plasma concentration-time curves of imatinib and imatinib-d8 can be found in Fig. 3. A summary of imatinib and imatinib-d8 pharmacokinetic parameters can be found in Table 2. 
The absorption of imatinib after oral administration of tablets was rapid, with a median $t_{\max }$ of $2 \mathrm{~h}$. The $C_{\max }$ of oral imatinib at steady state was $2.9 \pm 0.8 \mu \mathrm{g} / \mathrm{mL}$. The mean $\mathrm{AUC}_{0-24}$ for oral imatinib was $42.6 \pm 12.9 \mu \mathrm{g} \mathrm{h} / \mathrm{mL}$, and the mean $\mathrm{AUC}_{0 \text {-inf }}$ for imatinib-d8 was $0.015 \pm 0.007 \mu \mathrm{g} \mathrm{h} / \mathrm{mL}$. The $\mathrm{AUC}_{0 \text {-inf }}$ for imatinib-d8 normalized to a 400-mg imatinib dose was $60.5 \pm 26.4 \mu \mathrm{g} \mathrm{h} / \mathrm{mL}$. Individual plasma concentration-time curves demonstrated up to two secondary peaks after the $C_{\max }$, with different profiles for oral imatinib and intravenous imatinib-d8 (Supplementary Fig. 1). The ratios between the curves for oral imatinib and intravenous imatinib-d8 remained constant during the elimination phase, with a dose-normalized imatinib:imatinib- $\mathrm{d} 8$ ratio in plasma of 2.00 at $t=6 \mathrm{~h}$ and of 2.04 at $t=24 \mathrm{~h}$. The $t / 2$ and clearance of imatinib-d8 were $45.5 \mathrm{~h}$ and $7.6 \mathrm{~L} / \mathrm{h}$, respectively.

The absolute bioavailability $(F)$ of oral imatinib at steady state was calculated for each individual subject. Table $3 \mathrm{dem}-$ onstrates that the median absolute bioavailability of oral imatinib in cancer patients was 76\% (range 42-106\%).

\section{Discussion}

The current study describes results on the determination of the absolute bioavailability of oral imatinib following concomitant administration of a single intravenous stable isotopically labeled imatinib-d8 microdose.

Table $1 \quad$ Patient baseline characteristics

\begin{tabular}{lc}
\hline Characteristic & Patients \\
\hline Age, years & $65(52-72)$ \\
Gender, male & $4(67 \%)$ \\
Tumor type & \\
$\quad$ GIST & $6(100 \%)$ \\
Treatment setting & \\
Adjuvant & $3(50 \%)$ \\
Metastatic & $3(50 \%)$ \\
Previous surgery type & \\
Wedge partial resection of the stomach & $3(50 \%)$ \\
Partial small bowel resection & $1(17 \%)$ \\
Multiple resections* & $2(33 \%)$ \\
Time on imatinib treatment (in years) & $3.2(0.3-13.0)$ \\
Albumin (in g/L) & $44(42-47)$ \\
eGFR** (in mL/min) & $69(58-84)$ \\
\hline
\end{tabular}

Data are expressed as no. (\%) or median (range), as appropriate eGFR estimated glomerular filtration rate, GIST gastrointestinal stromal tumor

* One patient with wedge partial resection of the stomach and partial colon resection, and one patient with wedge partial resection of the stomach, splenectomy, and partial pancreas resection

** eGFR was calculated using the MDRD-4 formula
Table 2 Summary of imatinib and imatinib-d8 steady state pharmacokinetic parameters following concomitant administration of an oral imatinib dose $(400 \mathrm{mg})$ and an intravenous imatinib-d8 microdose $(100 \mu \mathrm{g})$ in cancer patients $(n=6)$

\begin{tabular}{|c|c|c|c|}
\hline Parameter & & Imatinib & $\begin{array}{l}\text { Imatinib- } \\
\mathrm{d} 8\end{array}$ \\
\hline \multirow[t]{2}{*}{$C_{\max }(\mu \mathrm{g} / \mathrm{mL})$} & Mean & 2.9 & 0.00051 \\
\hline & $\mathrm{CV}(\%)$ & 27.4 & 23.1 \\
\hline \multirow[t]{2}{*}{$C_{\min , 0 \mathrm{~h}}(\mu \mathrm{g} / \mathrm{mL})$} & Mean & 1.2 & N/A \\
\hline & $\mathrm{CV}(\%)$ & 27.4 & N/A \\
\hline \multirow[t]{2}{*}{$T_{\max }(\mathrm{h})$} & Median & 2 & N/A \\
\hline & Range & $1.5-2$ & N/A \\
\hline \multirow[t]{2}{*}{$\operatorname{AUC}_{0-24}(\mu \mathrm{g} \mathrm{h} / \mathrm{mL})$} & Mean & 42.6 & N/A \\
\hline & $\mathrm{CV}(\%)$ & 30.2 & N/A \\
\hline \multirow[t]{2}{*}{$\operatorname{AUC}_{0-\text { inf }}(\mu \mathrm{g} \mathrm{h} / \mathrm{mL})$} & Mean & $\mathrm{N} / \mathrm{A}$ & 0.015 \\
\hline & $\mathrm{CV}(\%)$ & N/A & 43.7 \\
\hline \multirow[t]{2}{*}{$t^{1} / 2(\mathrm{~h})$} & Mean & 34.1 & 45.5 \\
\hline & $\mathrm{CV}(\%)$ & 46.7 & 37.9 \\
\hline \multirow[t]{2}{*}{$k_{\mathrm{e}}\left(\mathrm{h}^{-1}\right)$} & Mean & 0.023 & 0.017 \\
\hline & $\mathrm{CV}(\%)$ & 27.5 & 28.1 \\
\hline \multirow[t]{2}{*}{$V_{\mathrm{d}} / F(\mathrm{~L})$} & Mean & 190 & N/A \\
\hline & $\mathrm{CV}(\%)$ & 26.7 & N/A \\
\hline \multirow[t]{2}{*}{$V_{\mathrm{d}}(\mathrm{L})$} & Mean & N/A & 462 \\
\hline & $\mathrm{CV}(\%)$ & N/A & 28.2 \\
\hline \multirow[t]{2}{*}{$\mathrm{CL} / F(\mathrm{~L} / \mathrm{h})$} & Mean & 4.2 & N/A \\
\hline & $\mathrm{CV}(\%)$ & 31.3 & N/A \\
\hline \multirow[t]{2}{*}{$\mathrm{CL}(\mathrm{L} / \mathrm{h})$} & Mean & N/A & 7.6 \\
\hline & $\mathrm{CV}(\%)$ & $\mathrm{N} / \mathrm{A}$ & 36.1 \\
\hline
\end{tabular}

$A U C_{0-i n f}$ area under the plasma concentration-time curve from time 0 to infinity; $A U C_{0-24}$ area under the plasma concentration-time curve from time 0 to $24 \mathrm{~h} ; C L / F$ apparent oral clearance; $C L$ apparent total body clearance; $C_{\max }$ maximum observed plasma concentration; $C_{\min }$ minimum observed plasma concentration at $t=0 \mathrm{~h} ; C V$ coefficient of variation; N/A not applicable; $t_{\max }$ time to reach maximum observed plasma concentration; $t_{1 / 2}$ terminal half-life; $V_{d} / F$ apparent volume of distribution after oral administration; $V_{d}$ apparent volume of distribution

Technically, the stable isotopically microdose trial design proved successful. For all patients, imatinib and imatinib-d8 concentrations could be simultaneously quantified in all collected plasma samples. The quantification of imatinib-d8 was not biased by high concentrations of unlabeled imatinib present in the same plasma sample. In theory, the use of deuterium as a label for the intravenous microdose may result in a kinetic isotope effect (KIE), caused by increased bond strength of the carbon-deuterium bond, as compared with the carbonhydrogen bond. The KIE may result in altered pharmacokinetics (e.g., altered metabolism) of the deuterium labeled drug, with an incorrect calculation of the absolute bioavailability as a result. [6] As the deuterium labels in the imatinibd8 structure were not located at metabolic hot spots in the imatinib molecule [17], the KIE was assumed to be negligible. 
Table 3 Absolute bioavailability of oral imatinib at steady state plasma pharmacokinetics $(n=6)$

\begin{tabular}{lll}
\hline & Imatinib tablet $(400 \mathrm{mg})$ & Intravenous imatinib-d8 $(100 \mu \mathrm{g})$ \\
\hline $\mathrm{AUC}_{0-24}(\mu \mathrm{g} \mathrm{h} / \mathrm{mL})(\mathrm{CV} \%)$ & $42.6(30.2)$ & $\mathrm{N} / \mathrm{A}$ \\
$\mathrm{AUC}_{0-\text { inf }}(\mu \mathrm{g} \mathrm{h} / \mathrm{mL})(\mathrm{CV} \%)$ & $\mathrm{N} / \mathrm{A}$ & $0.015(43.7)$ \\
Dose-normalized $\mathrm{AUC}_{0-\text { inf }}(\mu \mathrm{g} \mathrm{h} / \mathrm{mL})(\mathrm{CV} \%)$ & $\mathrm{N} / \mathrm{A}$ & $60.5(43.7)$ \\
$F(\%)($ median, range $)$ & $76(42-106)$ & - \\
\hline
\end{tabular}

As seen in Fig. 3, the curves for oral and intravenous imatinib demonstrate a parallel decline during the terminal elimination phase, with a constant mean dose-normalized imatinib:imatinib-d8 ratio in plasma of around 2.00, confirming that the KIE for the imatinib-d8 molecule was indeed negligible. The curves presented here demonstrate the validity of using the deuterium labeled imatinib-d 8 drug molecule for intravenous microdose administration.

The median absolute bioavailability was calculated to be $76 \%$ which was less than the $98 \%(87-111 \%$ (90\% confidence interval)) reported using a traditional two-period crossover design in healthy volunteers. [18] There might be different reasons for the lower absolute bioavailability found in this study as compared with the study in healthy volunteers. In the previous absolute bioavailability trial, healthy volunteers demonstrated considerable inter-subject variation in the absolute bioavailability of imatinib in twelve treated subjects. [1] The reasons for the high variability may be attributed to intersubject variations in the activity of cytochrome $\mathrm{P} 450$ isoenzyme 3 A4 (CYP3A4), a major enzyme in the biotransformation of imatinib. [1] It could be that the lower bioavailability found in our study may solely be a result of this interpatient variability, as both studies demonstrate a relatively large inter-subject variability in small study populations (6 and 12 subjects included for each trial, respectively). An alternative theory may be that the absolute bioavailability actually differs between healthy volunteers and GIST patients. If so, there might be a change present at baseline, or a change developed during prolonged treatment with imatinib. In theory, GIST disease status may negatively influence the absorption of drug into the systemic circulation, resulting in a lower absolute bioavailability at baseline. In a previous study, patients with a prior major gastrectomy had a significantly lower $C_{\min }$, while other types of surgery were not associated with decreased pharmacokinetic exposure. [19] However, in another observational study, type of surgery and extent of resection were not predictive of low imatinib concentrations. [20] Our study patient population consisted of patients without prior major gastrectomy (Table 1), and results were therefore not likely to be influenced by prior surgery.
Fig. 2 Schematic overview of the imatinib absolute bioavailability microdose trial design

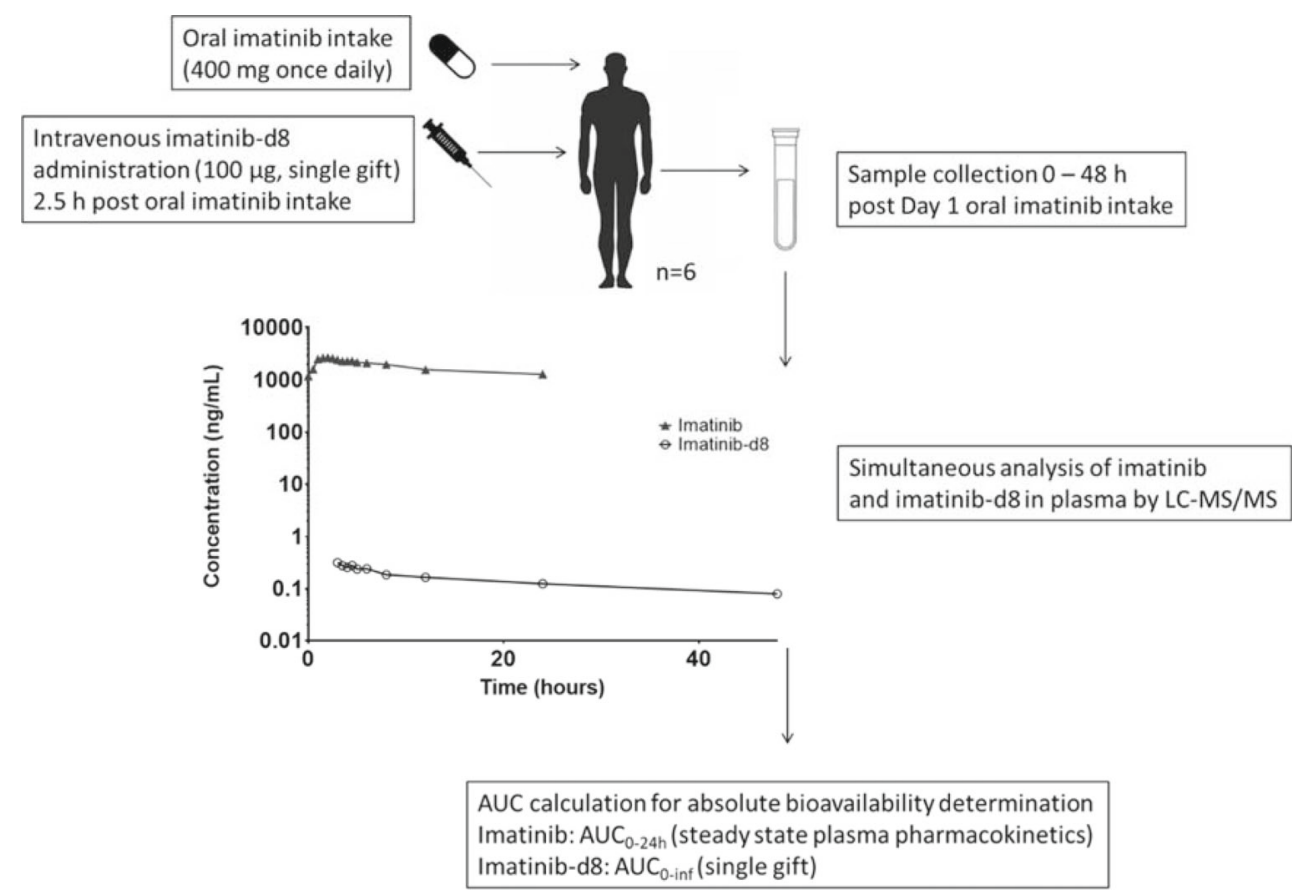

Abbreviations: LC-MS/MS, liquid chromatography coupled to tandem mass spectrometry; $\mathrm{AUC}_{0-24 \mathrm{~h}}$, area under the plasma-time curve up to 24 hours, $\mathrm{AUC}_{0 \text {-inf, }}$, area under the plasma-time curve extrapolated to infinity 
Another explanation for the lower bioavailability might be a change developed during prolonged imatinib treatment. Imatinib pharmacokinetic parameters have been described to change from early to later treatment phase, with a trend towards increased imatinib clearance after long-term exposure $[21,22]$, although this finding could not be reproduced in other studies. [20, 23] In our study population, all patients were on imatinib treatment for several months or years (median 3.2 years, range $0.3-13.0$ years), and the clearance was similar to the clearance observed during the first month of treatment as described by Judson et al. ( $7.6 \mathrm{~L} / \mathrm{h}$ vs. $9.2 \mathrm{~L} / \mathrm{h}$ ). [21] Since pharmacokinetic exposure to imatinib has been related to treatment efficacy [24], therapeutic drug monitoring has been implemented in our hospital. Therefore, in case of an increased clearance and thus a lower pharmacokinetic exposure, dose escalations have probably been performed. These patients were not eligible for inclusion in this trial, which might explain the absence of an observed increase in drug clearance as a result of selection bias. Furthermore, if a change in clearance was found, this would not have explained the lower value for absolute bioavailability, as the oral and intravenous dose are co-administered during a single-dose event, eliminating inter-dose variability.

In a prospective pharmacokinetic trial on imatinib plasma concentrations in GIST patients, a reduced exposure of approximately $30 \%$ to imatinib was observed after long-term treatment ( $>90$ days), most likely due to reduced drug absorption over time. [25] This reduced exposure may potentially be a result of the lower absolute bioavailability that we observed in our trial. Although different theories for this reduced absorption and/or bioavailability do exist (e.g., changed activity or expression of drug transporters involved in active transport, upregulation of CYP3A4) [25], none has been confirmed to date.

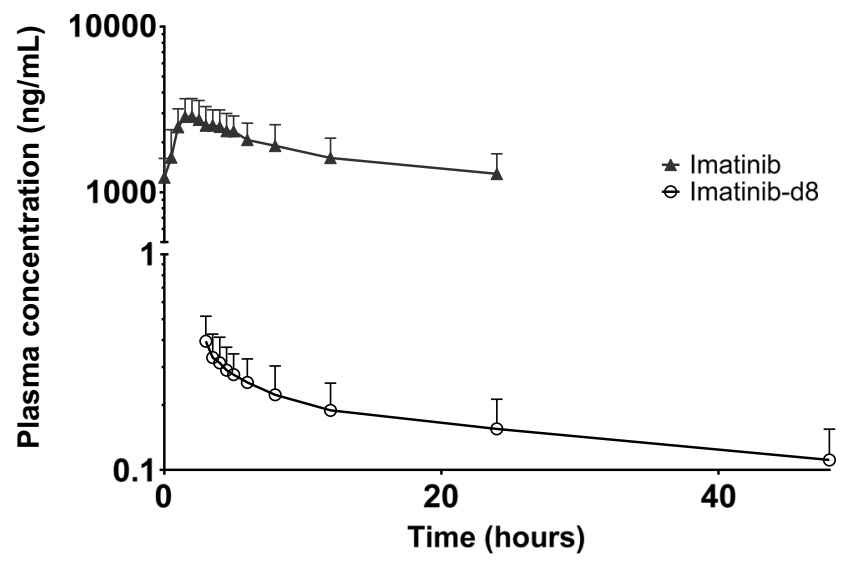

Fig. 3 Plasma concentration-time curves of imatinib and imatinib-d8 (mean \pm SD) following oral administration of $400 \mathrm{mg}$ imatinib dose at $t=0 \mathrm{~h}$ and intravenous administration of a $100 \mu \mathrm{g}$ imatinib-d 8 microdose at $t=2.5 \mathrm{~h}$ in patients $(n=6)$ displaying steady state imatinib plasma pharmacokinetics
Finally, the lower bioavailability found in our study could potentially be explained by the fact that patients ingested imatinib concomitant with food (according to the label), while the previous absolute bioavailability study has been performed under fasted conditions. Although a previous food-effect study concluded that food did not affect imatinib pharmacokinetics to a clinically relevant extent, $C_{\max }$ and $\mathrm{AUC}_{0-24 \mathrm{~h}}$ decreased $15 \%$ and $9 \%$, respectively, after concomitant intake with a high-fat meal compared with the fasted state. [26]

Interestingly, the individual plasma concentration-time curves demonstrated up to two secondary peaks after the $C_{\max }$, with different profiles for oral imatinib and intravenous imatinib-d8 (Supplementary Fig. 1). Previous research on imatinib has not demonstrated enterohepatic cycling of imatinib. Another explanation for these peaks might be bile secretion triggered by food intake, resulting in acceleration of drug solubility in the gastrointestinal lumen, although food has been described to have no relevant impact on the rate or extent of bioavailability. [27]

By using the stable isotopically labeled microdose trial design, a number of dose events and collected plasma samples were reduced by half, as compared with the previously performed absolute bioavailability trial using a conventional crossover design. [18] This reduction may aid to perform this trial in patients in the future, as it offers the possibility to be combined with a phase I/II trial in patients without adding a separate intravenous dose event. The microdose trial design using a stable isotopically labeled drug will only mildly increase patient burden by adding a single intravenous microdose administration to the study procedures. This minor adjustment may result in increased and more relevant knowledge on the pharmacokinetics of a novel drug product in an early stage of clinical drug development.

\section{Conclusion}

The absolute bioavailability of oral imatinib in cancer patients during steady state pharmacokinetics was successfully determined using a stable isotopically labeled microdose trial. This study demonstrates the potential to use a stable isotopically labeled microdose in combination with LC-MS/MS for the assessment of absolute bioavailability. In addition, the potential added value of performing an absolute bioavailability study in the intended patient population for clinical use during steady state pharmacokinetics was demonstrated by comparing the results obtained with a previously performed absolute bioavailability trial in healthy volunteers.

Authors' contributions J.R., H.R., B.N., A.H., J.B., and N.S. were involved in conception and design of the study. J.R., S.G., N.V., A.H., J.B., 
and N.S. were involved in acquisition, analysis, and interpretation of the data. J.R. drafted the manuscript and all other authors critically revised the manuscript. All authors gave final approval for the manuscript to be published. N.S. was the principal investigator.

\section{Compliance with ethical standards}

Competing interests The authors declare that they have no competing interests.

Open Access This article is licensed under a Creative Commons Attribution 4.0 International License, which permits use, sharing, adaptation, distribution and reproduction in any medium or format, as long as you give appropriate credit to the original author(s) and the source, provide a link to the Creative Commons licence, and indicate if changes were made. The images or other third party material in this article are included in the article's Creative Commons licence, unless indicated otherwise in a credit line to the material. If material is not included in the article's Creative Commons licence and your intended use is not permitted by statutory regulation or exceeds the permitted use, you will need to obtain permission directly from the copyright holder. To view a copy of this licence, visit http://creativecommons.org/licenses/by/4.0/.

\section{References}

1. Liu G, Franssen E, Fitch MI, Warner E (1997) Patient preferences for oral versus intravenous palliative chemotherapy. J Clin Oncol $15: 110-115$

2. Benjamin L, Cotté FE, Philippe C, Mercier F, Bachelot T, VidalTrécan G (2012) Physicians' preferences for prescribing oral and intravenous anticancer drugs: a discrete choice experiment. Eur J Cancer 48:912-920

3. Herbrink M, Nuijen B, Schellens JHM, Beijnen JH (2015) Variability in bioavailability of small molecular tyrosine kinase inhibitors. Cancer Treat Rev 41:412-422

4. European Medicines Agency. Clinical pharmacology and pharmacokinetics: questions and answers [cited 2019 Apr 15]. Available from: https://www.ema.europa.eu/en/human-regulatory/researchdevelopment/scientific-guidelines/clinical-pharmacologypharmacokinetics/clinical-pharmacology-pharmacokineticsquestions-answers

5. U.S. Food and Drug Administration. Bioavailability Studies Submitted in NDAs or INDs - General Considerations Guidance for Industry [cited 2020 Apr 21]. Available from: https://www.fda.gov/media/121311/download

6. Lappin G, Rowland M, Garner RC (2006) The use of isotopes in the determination of absolute bioavailability of drugs in humans. Expert Opin Drug Metab Toxicol 2:419-427

7. European Medicines Agency. ICH M3(R2)-guidance on nonclinical safety studies for the conduct of human clinical trials and marketing authorization for pharmaceuticals. [cited 2019 Apr 15]. Available from: http:/www.ich.org/fileadmin/Public_Web_Site/ ICH Products/Guidelines/Multidisciplinary/M3 R2/Step4/M3 R2 Guideline.pdf

8. Xu X, Jiang H, Christopher LJ, Shen JX, Zeng J, Arnold ME (2014) Sensitivity-based analytical approaches to support human absolute bioavailability studies. Bioanalysis 6:497-504

9. Burt T, John CS, Ruckle JL, Vuong LT (2017) Phase-0/ microdosing studies using PET, AMS, and LC-MS/MS: a range of study methodologies and conduct considerations. Accelerating development of novel pharmaceuticals through safe testing in humans-a practical guide. Expert Opin Drug Deliv 657-72
10. Lappin G (2016) Approaches to intravenous clinical pharmacokinetics: recent developments with isotopic microtracers. J Clin Pharmacol 14:657-672

11. European Medicines Agency. Glivec-summary of product characteristics.[cited 2020 Apr 21]. Available from: https://www. ema.europa.eu/en/documents/product-information/glivec-eparproduct-information_en.pdf

12. Roosendaal J, Venekamp N, Lucas L, Rosing H, Beijnen JH (2020) Development and validation of an LC-MS/MS method for the quantification of imatinib and imatinib-d8 in human plasma for the support of an absolute bioavailability microdose trial. Pharmazie 75:136-141

13. U.S. Food and Drug Administration. Guidance for industry: bioanalytical method validation. [cited 2018 Jul 24]. Available from: https://www.fda.gov/downloads/drugs/guidances/ ucm070107.Pdf

14. European Medicines Agency. Guideline on bioanalytical method validation. [cited 2018 May 4]. Available from: http://www.ema. europa.eu/ema/index.jsp?curl=pages/includes/document/ document_detail.jsp?webContentId=WC500109686\&mid= WC0b01ac058009a3dc

15. R Development Core Team. R Core Team. R: a language and environment for statistical computing. Available from: http:// www.r-project.org

16. Rowland M, Tozer TN (1995) Clinical pharmacokinetics-concepts and applications, 3rd edn

17. Gschwind HP, Pfaar U, Waldmeier F, Zollinger M, Sayer C, Gross $\mathrm{G}$ (2005) Metabolism and disposition of imatinib mesylate in healthy volunteers Abstract. Drug Metab Dispos 33:1503-1512

18. Peng B, Dutreix C, Mehring G, Hayes MJ, Ben-Am M, Seiberling M, Pokorny R, Capdeville R, Lloyd P (2004) Absolute bioavailability of imatinib (Glivec $($ ) orally versus intravenous infusion. J Clin Pharmacol 44:158-162

19. Yoo C, Ryu MH, Kang BW, Yoon SK, Ryoo BY, Chang HM, Lee JL, Beck MY, Kim TW, Kang YK (2010) Cross-sectional study of imatinib plasma trough levels in patients with advanced gastrointestinal stromal tumors: impact of gastrointestinal resection on exposure to imatinib. J Clin Oncol 28:1554-1559

20. Farag S, Verheijen RB, Martijn Kerst J, Cats A, Huitema ADR, Steeghs N (2017) Imatinib pharmacokinetics in a large observational cohort of gastrointestinal stromal tumour patients. Clin Pharmacokinet 56:287-292

21. Judson I, Ma P, Peng B, Verweij J, Racine A, Di Paola ED et al (2005) Imatinib pharmacokinetics in patients with gastrointestinal stromal tumour: a retrospective population pharmacokinetic study over time. EORTC Soft Tissue and Bone Sarcoma Group. Cancer Chemother Pharmacol 55:379-386

22. Bins S, Eechoute K, Kloth JSL, de Man FM, Oosten AW, de Bruijn P, Sleijfer S, Mathijssen RHJ (2017) Prospective analysis in GIST patients on the role of alpha-1 acid glycoprotein in imatinib exposure. Clin Pharmacokinet 56:305-310

23. Yoo C, Ryu MH, Ryoo BY, Beck MY, Chang HM, Lee JL, Kim TW, Kang YK (2012) Changes in imatinib plasma trough level during long-term treatment of patients with advanced gastrointestinal stromal tumors: correlation between changes in covariates and imatinib exposure. Investig New Drugs 30:1703-1708

24. Demetri GD, Wang Y, Wehrle E, Racine A, Nikolova Z, Blanke CD, Joensuu H, von Mehren M (2009) Imatinib plasma levels are correlated with clinical benefit in patients with unresectable/ metastatic gastrointestinal stromal tumors. J Clin Oncol 27:31413147

25. Eechoute K, Fransson MN, Reyners AK, De Jong FA, Sparreboom A, Van Der Graaf WTA et al (2012) A long-term prospective population pharmacokinetic study on imatinib plasma concentrations in GIST patients. Clin Cancer Res 18:5780-5787 
26. U.S. Food and Drug Administration. Gleevec-clinical pharmacology and biopharmaceutics review. p. 67-70. [cited 2020 Apr 21] Available from: https://www.accessdata.fda.gov/drugsatfda_docs/ nda/2001/21-335_Gleevec_biopharmr_P1.pdf
27. Peng B, Lloyd P, Schran H (2005) Clinical pharmacokinetics of imatinib. Clin Pharmacokinet 44:879-894

Publisher's note Springer Nature remains neutral with regard to jurisdictional claims in published maps and institutional affiliations. 